\title{
The management of infection and colonization due to methicillin-resistant Staphylococcus aureus: A CIDS/CAMM position paper
}

\author{
Andrew E Simor MD FRCPC ${ }^{1,2}$, Mark Loeb MD FRCPC ${ }^{3,4}$ and the CIDS/CAMM Guidelines Committee ${ }^{5}$
}

\begin{abstract}
AE Simor, M Loeb. The management of infection and colonization due to methicillin-resistant Staphylococcus aureus: A CIDS/CAMM position paper. Can J Infect Dis 2004;15(1):39-48.
\end{abstract}

Methicillin-resistant Staphylococcus aureus (MRSA) is being seen with greater frequency in most hospitals and other health care facilities across Canada. The organism may cause life-threatening infections and has been associated with institutional outbreaks. Several studies have confirmed that MRSA infection is associated with increased morbidity and mortality compared with infections caused by susceptible strains, even when the presence of comorbidities is accounted for. Treatment of MRSA infection is complicated by the fact that these organisms are resistant to multiple antimicrobial agents, so treatment options are limited. The effectiveness of decolonization therapy (attempting to eradicate MRSA carriage) is also uncertain. This paper reviews the medical management of MRSA infections, discusses the potential role of decolonization and provides an overview of evidence to support recommended infection control practices.

Key Words: Methicillin resistance; MRSA; Staphylococcus aureus
La prise en charge de l'infection et de la colonisation secondaires au Staphylococcus aureus méthicillinorésistant : Une déclaration de principe de la SMCI et de l'ACMM

La fréquence des cas de Staphylococcus aureus méthicillinorésistant (SAMR) augmente dans la plupart des hôpitaux et des autres établissements de soins du Canada. L'organisme peut provoquer des infections mettant en jeu le pronostic vital et s'associe à des flambées nosocomiales. Plusieurs études confirment que l'infection à SAMR s'associe à une augmentation de la morbidité et de la mortalité par rapport aux infections causées par des souches susceptibles, même en tenant compte de la présence de comorbidités. Le traitement de l'infection à SAMR se complique par le fait que ces organismes résistent à de multiples antimicrobiens, ce qui limite les possibilités de traitement. L'efficacité du traitement par décolonisation (une tentative d'éradiquer le portage de SAMR) est également incertaine. Le présent article permet d'analyser la prise en charge médicale des infections à SAMR, traite du rôle potentiel de la décolonisation et fournit un aperçu des données probantes permettant de soutenir les pratiques recommandées de contrôle de l'infection.
$\mathrm{T}$ he past few decades have witnessed the emergence of methicillin-resistant Staphylococcus aureus (MRSA) as a major hospital-acquired pathogen worldwide (1-4). Although MRSA was first reported in Canada in 1981 (5), MRSA rates in Canadian hospitals have only increased substantially in the last few years. The Canadian Nosocomial Infection Surveillance Program (CNISP) reported that the incidence of MRSA in sentinel hospitals across the country increased from a mean of 0.9 per $100 \mathrm{~S}$ aureus isolates in 1995 to 8.2 per 100 isolates in 2001, and from 0.5 cases per 1000 admissions in 1995 to 4.4 per 1000 admissions in $2001(6,7)$. Part of this increase may have been related to more frequent screening for MRSA colonization in high risk patients (8). However, a fourfold increase in MRSA infection rates was also observed (from 0.3 infections per 1000 admissions in 1995 to 1.2 infections per 1000 admissions in 2001) (6,7).
Although there have been recent reports describing community-onset MRSA in the United States, CNISP data would suggest that MRSA remains predominantly a hospital-acquired pathogen in Canada (6). Nevertheless, it would seem reasonable to expect that an increase in MRSA rates in hospitals will eventually lead to spread of the organism in long term care facilities and the community. In Canada, community-acquired MRSA has been reported most frequently in western Canada, especially among native Aboriginals and intravenous drug users $(9,10)$. Recognized risk factors for MRSA acquisition have included previous hospitalization, admission to an intensive care unit, prolonged hospital stay, proximity to another patient with MRSA, older age, invasive procedures, presence of wounds or skin lesions, and prior antimicrobial therapy $(11-15)$.

${ }^{1}$ Departments of Medicine and Microbiology, Sunnybrook and Women's College Health Sciences Centre, Toronto, Ontario; ${ }^{2}$ Department of Laboratory Medicine and Pathobiology, University of Toronto, Toronto, Ontario; ${ }^{3}$ Hamilton Regional Laboratory Program, Hamilton, Ontario; ${ }^{4}$ Departments of Pathology and Molecular Medicine, and Clinical Epidemiology and Biostatistics, McMaster University, Hamilton, Ontario;

${ }^{5}$ CIDS/CAMM Guidelines Committee members: G Evans, S King, M Laverdiere, L Nicolle, P Phillips, C Quan, C Rotstein

Correspondence and reprints: Dr Andrew E Simor, Department of Microbiology, Sunnybrook and Women's College Health Sciences Centre,

B121-2075 Bayview Avenue, Toronto, Ontario M4N 3M5. Telephone 416-480-4549, fax 416-480-6845,

e-mail andrew.simor@swchsc.on.ca 
TABLE 1

Randomized, controlled trials of antimicrobial agents for the treatment of infections caused by methicillin-resistant Staphylococcus aureus (MRSA)

\begin{tabular}{|c|c|c|c|c|c|}
\hline Reference (year) & n (total) & Evaluable patients with MRSA (n) & MRSA infections & Antimicrobial agents & Clinical success $(\%)^{*}$ \\
\hline \multirow[t]{2}{*}{$41(1988)$} & \multirow[t]{2}{*}{21} & \multirow[t]{2}{*}{21} & \multirow{2}{*}{$\begin{array}{l}\text { 'Invasive', } \\
\text { septicemia }\end{array}$} & Teicoplanin, & $7 / 12(58)$ \\
\hline & & & & vancomycin & $6 / 9(67)$ \\
\hline \multirow[t]{2}{*}{$51(1992)$} & \multirow[t]{2}{*}{101} & \multirow[t]{2}{*}{47} & \multirow{2}{*}{$\begin{array}{c}\text { Bacteremia, } \\
\text { skin or soft tissue }\end{array}$} & TMP-SMX, & $21 / 21(100)$ \\
\hline & & & & vancomycin & $26 / 26(100)$ \\
\hline \multirow[t]{2}{*}{73 (1999) } & \multirow[t]{2}{*}{562} & \multirow[t]{2}{*}{15} & \multirow[t]{2}{*}{ Skin or soft tissue } & $\mathrm{Q} / \mathrm{D}$ & $7 / 9(78)$ \\
\hline & & & & vancomycin & $3 / 6(50)$ \\
\hline \multirow[t]{2}{*}{$76(2000)$} & \multirow[t]{2}{*}{171} & \multirow[t]{2}{*}{38} & \multirow{2}{*}{$\begin{array}{l}\text { Nosocomial } \\
\text { pneumonia }\end{array}$} & $\mathrm{Q} / \mathrm{D}$ & $6 / 20(31)$ \\
\hline & & & & vancomycin & 8/18 (44) \\
\hline \multirow[t]{2}{*}{$86(2001)$} & \multirow[t]{2}{*}{396} & \multirow[t]{2}{*}{32} & \multirow{2}{*}{$\begin{array}{l}\text { Nosocomial } \\
\text { pneumonia }\end{array}$} & \multirow{2}{*}{$\begin{array}{l}\text { Linezolid, } \\
\text { vancomycin }\end{array}$} & $15 / 23(65)$ \\
\hline & & & & & $7 / 9(78)$ \\
\hline \multirow[t]{2}{*}{$85(2002)$} & \multirow[t]{2}{*}{460} & \multirow[t]{2}{*}{108} & \multirow{2}{*}{$\begin{array}{c}\text { Skin or soft tissue, } \\
\text { pneumonia, } \\
\text { urinary tract }\end{array}$} & \multirow{2}{*}{$\begin{array}{l}\text { Linezolid, } \\
\text { vancomycin }\end{array}$} & $41 / 56(73)$ \\
\hline & & & & & $38 / 52(73)$ \\
\hline
\end{tabular}

${ }^{*}$ None of these studies demonstrated a statistically significant difference in outcomes (clinical success rates) between the comparator antimicrobial agents. Q/D Quinupristin-dalfopristin; TMP-SMX Trimethoprim-sulphamethoxazole

If MRSA only colonized patients, there would be little reason for concern. However, $20 \%$ to $60 \%$ of patients identified as being colonized with MRSA in hospital subsequently develop an MRSA infection (12). Using standard criteria for identification of infections, CNISP data indicated that approximately $31 \%$ of patients with MRSA in Canadian hospitals were infected (7). In certain high risk populations, staphylococcal infections including bacteremia occur more frequently following colonization with MRSA than after colonization with susceptible strains of $S$ aureus (16). Moreover, MRSA does not merely replace susceptible strains of $S$ aureus as a hospitalacquired pathogen, but rather, it appears to add substantially to the total burden of nosocomial infections $(17,18)$. Although the results are somewhat controversial, several studies have also indicated increased mortality and prolonged hospitalization associated with MRSA infections (19-21). After adjustment for comorbidities, methicillin resistance has been found to be a significant independent risk factor for mortality in bacteremic patients (21-23).

Several studies have also documented the economic impact of MRSA in hospitalized patients, demonstrating increased costs associated with managing infections and with the implementation of control measures $(19,24,25)$. The average attributable cost of managing an MRSA infection in a Canadian hospital was estimated to be approximately $\$ 14,360$, whereas costs associated with managing a patient with MRSA colonization were approximately $\$ 1,363$ per hospital admission (25).

The first strain of $S$ aureus, an MRSA, with reduced susceptibility to vancomycin was reported from Japan in 1996 $(26,27)$. Since then, such strains with vancomycin minimum inhibitory concentrations (MIC) of $8 \mu \mathrm{g} / \mathrm{mL}$ to $16 \mu \mathrm{g} / \mathrm{mL}$ (vancomycin-intermediate $S$ aureus [VISA]) have been reported from several countries in southeast Asia, South America, Europe and the United States (28-30). Of even greater concern has been the recent identification of two infections caused by MRSA with high level resistance to vancomycin (MIC greater than $128 \mu \mathrm{g} / \mathrm{mL}$; vancomycin-resistant $S$ aureus [VRSA]), mediated by the vanA gene determinant found in vancomycin-resistant enterococci $(31,32)$. These developments have emphasized the need for appropriate use of glycopeptides and other antimicrobial agents in the management of patients with MRSA. This paper reviews options for the treatment of patients with MRSA infection or colonization. The treatment options should be considered appropriate for hospitalized patients as well as for out-patients, and for those residing in long term care facilities.

\section{TREATMENT OF MRSA INFECTION}

Few clinical trials designed to determine optimal antimicrobial therapy for MRSA infection have been published (Table 1). In all of these comparative studies, vancomycin was considered to be standard therapy. Inclusion criteria, sites and severity of infection, and outcome measures varied from study to study. Each of the studies included relatively small numbers of patients with documented infection due to MRSA and failed to show any statistically significant differences between the agents evaluated. In the past few years, several new agents with in vitro activity against resistant Gram-positive organisms have become available but clinical experience with these drugs against serious MRSA infections, including bacteremia, is still limited.

\section{Glycopeptides}

Vancomycin is currently considered the treatment of choice for serious MRSA infections (33-36). Unfortunately, vancomycin is potentially more toxic and probably less effective than a betalactam antibiotic would be if the infection were caused by a susceptible strain of $S$ aureus (35,37-39). Vancomycin has a relatively slow bactericidal effect against staphylococci, thereby possibly reducing its clinical effectiveness (40). The emergence of vancomycin resistance in MRSA and in enterococci is an additional reason for concern $(27,31,32,35)$. Teicoplanin, a glycopeptide agent structurally related to vancomycin, is as active in vitro as vancomycin against MRSA but does not appear to offer any significant advantages for the treatment of MRSA infections (Table 1) (41,42).

\section{Clindamycin}

Clindamycin has been used successfully in a small number of patients infected with susceptible strains of MRSA (43). However, most MRSA strains are resistant to clindamycin $(6,44,45)$ and the drug should probably not be used in the treatment of systemic or bacteremic infections where MRSA is known or suspected to be a pathogen. In addition, 
staphylococci resistant to macrolides should also be considered resistant to clindamycin based on the presence of rRNA methylases specified by erm genetic determinants (46).

\section{Minocycline}

Minocycline is a semisynthetic derivative of tetracycline with in vitro activity against many strains of MRSA. Resistance to tetracycline in MRSA is common in many parts of the world and may be associated with cross-resistance to doxycycline and minocycline $(44,47)$. Minocycline has been used in the management of both infected and colonized patients with MRSA, although clinical experience with the drug in these settings has been limited. There have been case reports describing the successful treatment of MRSA endocarditis with minocycline in patients who had failed to respond to other antimicrobial agents $(48,49)$.

\section{Trimethoprim-sulphamethoxazole}

Trimethoprim-sulphamethoxazole (TMP-SMX) has been used to treat a small number of patients with MRSA bacteremia, endocarditis and meningitis (50). In a randomized, controlled trial, TMP-SMX (used in 21 patients) was found to be as effective as vancomycin (used in 26 patients) for those with MRSA infections including bacteremias, although TMP-SMX appeared to be less effective for the treatment of patients with infection due to susceptible strains of $S$ aureus (Table 1) (51). Increasing resistance to TMP-SMX in MRSA has been reported, limiting its use (44). Currently, approximately $40 \%$ to $50 \%$ of MRSA isolates in Canadian hospitals are resistant to this agent (6).

\section{Fluoroquinolones}

When fluoroquinolones such as ciprofloxacin were first introduced into clinical practice, staphylococci were uniformly susceptible to this class of drugs. There was optimism about the role fluoroquinolones might play in the treatment of MRSA infections and the eradication of MRSA colonization (52). However, rapid emergence of ciprofloxacin resistance in staphylococci, especially in MRSA, occurred $(53,54)$. Currently, the vast majority of MRSA isolates in Canada are resistant to ciprofloxacin (6).

More recently, newer fluoroquinolones with enhanced in vitro activity against Gram-positive organisms have become available. Although drugs such as moxifloxacin, gatifloxacin and gemifloxacin have enhanced activity against staphylococci and MRSA ( $\mathrm{MIC}_{90}, 0.5$ to $\left.8.0 \mu \mathrm{g} / \mathrm{mL}\right)(55-58)$, there have been no published reports describing the use of these agents for the treatment of MRSA infections. Currently available fluoroquinolones are not recommended for the treatment of MRSA infections.

\section{Rifampin}

Rifampin has bactericidal in vitro activity against staphylococci, including MRSA (59). However, there is rapid emergence of resistance if this drug is used alone (60). Therefore, it has been suggested that if rifampin is to be used, it should be used in combination with another active agent. Such drug combinations may result in synergistic activity against staphylococci $(61,62)$. The combination of rifampin and vancomycin has been used successfully in the treatment of infections where vancomycin alone appeared to fail (63). However, the combination of these two drugs may be antagonistic in vitro (64). The clinical relevance of this observation is uncertain but it has been recommended that combination therapy with rifampin be reserved for patients not responding to vancomycin alone (34).

\section{Fusidic acid}

Fusidic acid interferes with protein synthesis and is bactericidal against staphylococci at high concentrations (65). The drug is available topically, orally and as an intravenous formulation. Administration of the drug intravenously has been associated with significant toxicity (granulocytopenia, hepatotoxicity, thrombophlebitis). As with rifampin, resistance to fusidic acid often emerges rapidly when the drug is used alone, particularly when used to treat chronic infections (65-67). In a rabbit model of endocarditis due to MRSA, fusidic acid alone was ineffective and was associated with the emergence of resistance to the drug; no resistance emerged if fusidic acid was used in combination with vancomycin, although the combination was no more effective than vancomycin alone (67). In a small series of patients with a variety of MRSA infections, $67 \%$ of the infections were cured when intravenous fusidic acid was used in combination with vancomycin, an aminoglycoside, or a fluoroquinolone (68). However, resistance to fusidic acid in association with treatment failure has also been reported to occur in a patient with MRSA infection treated with a combination of vancomycin and fusidic acid (69). Consequently, the role of fusidic acid in the management of MRSA infections remains uncertain.

\section{Quinupristin-dalfopristin}

Quinupristin-dalfopristin is the first of the streptogramin compounds to become available. The combination of quinupristin and dalfopristin is synergistic and bactericidal against most Gram-positive cocci, including MRSA (70). The drug also appears to be active against most strains of lincosamide- and erythromycin-resistant MRSA (71). Only a parenteral formulation of quinupristin-dalfopristin is available.

There has been a small number of case reports, open label studies and clinical trials that have demonstrated the efficacy of quinupristin-dalfopristin in treating a variety of MRSA infections. In many patients, quinupristin-dalfopristin was given in combination with other drugs (such as vancomycin or rifampin) $(70,72-74)$ and in some cases, the drug was used in patients who had failed prior therapy $(74,75)$. In one multicentre, randomized, controlled trial, quinupristin-dalfopristin was compared with vancomycin for the treatment of nosocomial pneumonia (Table 1) (76). In the 38 patients in whom MRSA infection was identified, there was no significant difference in outcome with either agent. Two multicentre trials of quinupristin-dalfopristin in hospitalized patients with complicated skin and soft tissue infections were reported by Nichols et al (Table 1) (73). Although a total of 562 patients were enrolled in these studies, only 15 with documented MRSA infection were evaluable. No difference in outcome was found in the quinupristin-dalfopristin-treated group compared with those treated with vancomycin.

In the relatively short time since the introduction of quinupristin-dalfopristin, the development of streptogramin resistance in MRSA has been reported $(77,78)$. In at least one case, resistance to quinupristin-dalfopristin emerged in an MRSA isolate with reduced susceptibility to vancomycin (78).

\section{Linezolid}

Oxazolidinones are chemically distinct synthetic antibacterial agents that inhibit protein synthesis by binding to the $50 \mathrm{~S}$ 
ribosomal subunit and thereby inhibit the binding of mRNA to the ribosome at the initiation of translation. Linezolid is the first of this class of compounds to become available but there are several other related agents under development. The drug may be administered intravenously or orally. Linezolid is active in vitro against Gram-positive cocci, including staphylococci and MRSA, with $\mathrm{MIC}_{90}$ generally reported to be approximately $2 \mu \mathrm{g} / \mathrm{mL}$ (79). However, it is important to note that linezolid has bacteriostatic activity against staphylococci and there is no synergy in vitro if linezolid is combined with vancomycin or rifampin (80). Prolonged treatment with linezolid has been associated with the development of reversible thrombocytopenia and myelosuppression (81). Linezolid has been used for the treatment of a variety of MRSA infections, although there is still little experience with the use of this drug in bacteremic infections (82). Two cases of MRSA endocarditis failed to respond to treatment with intravenous linezolid but were subsequently treated successfully with other agents (83). The first clinical MRSA isolate resistant to linezolid was recently reported (84).

There have been two published randomized, controlled trials with linezolid in patients with MRSA infections (Table 1). Stevens et al (85) randomized 460 patients with suspected MRSA infections to receive either linezolid (600 mg bid) or vancomycin (1 gm bid). MRSA infection was confirmed in 108 evaluable patients; none of these patients was bacteremic. The two drugs demonstrated equal efficacy. Rubinstein et al (86) conducted a multicentre, randomized, controlled trial comparing linezolid with vancomycin for the treatment of nosocomial pneumonia. MRSA was recovered from 31 of the 296 patients enrolled in the study. No significant difference in outcome was found in this subset of patients (nor was there a difference in outcome for the entire study population). Preliminary results of a study comparing linezolid with vancomycin for treatment of hospitalized patients with MRSA infection indicated that patients randomized to treatment with linezolid could be discharged home earlier because of the availability of an oral formulation of the drug (87).

\section{Investigational compounds}

The mechanism of beta-lactam resistance in MRSA involves the production of penicillin-binding protein (PBP) $2 \mathrm{a}$ with low affinity to beta-lactam compounds specified by the mecA gene. However, new beta-lactams have recently been developed that appear to bind to PBP 2a in staphylococci. RWJ54428 is an investigational parenteral cephalosporin that is able to bind to PBP 2a and has been found to be active against MRSA, including strains with reduced susceptibility to vancomycin $\left(\mathrm{MIC}_{90}, 2 \mu \mathrm{g} / \mathrm{mL}\right)$ (88). New carbapenems (eg, L-695,256 and SM-17466) able to bind to PBP 2a with a high degree of affinity have also been developed. These drugs appear to be active in vitro against MRSA strains $(89,90)$ and L-695,256 appears to be as effective as vancomycin in an animal model of endocarditis (89).

New glycopeptides are being evaluated, including a compound designated oritavancin (LY333328) which appears to have in vitro activity against MRSA comparable to that of vancomycin, but is more rapidly bactericidal (91). New oxazolidinone agents (such as AZD2563) are also being evaluated (92).

Glycylcyclines are derivatives of tetracycline or minocycline, and have been found to have activity against many tetracycline-resistant organisms, including MRSA (93).
Newer fluoroquinolones and desfluoroquinolones (eg, garenoxacin, formerly BMS 284756) have been developed with enhanced activity against Gram-positive organisms (94). These agents appear to be more active in vitro against staphylococci, including MRSA, than ciprofloxacin, levofloxacin and gatifloxacin. Sitafloxacin is an investigational fluoroquinolone that has been used to treat MRSA infections in a small number of patients. In an open label study involving 11 patients with MRSA infections who failed therapy with a glycopeptide, treatment with sitafloxacin resulted in a successful outcome in four patients, treatment failure in six and indeterminate outcome in one patient (95).

Daptomycin (LY146032) is an acidic lipopeptide that inhibits synthesis of lipotechoic acid. It appears to be bactericidal against staphylococci with in vitro activity that is comparable to that of glycopeptides such as vancomycin and teicoplanin $(96,97)$. It has also been found to have activity against strains of MRSA with reduced susceptibility to vancomycin (97). Daptomycin appears to be effective in treating MRSA infections in a number of animal models but there is limited clinical experience, and concerns about toxicity may limit its use in humans $(98,99)$.

Everninomicins are oligosaccharide antimicrobials with broad-spectrum activity against Gram-positive organisms. Evernimicin (formerly SCH 27899) is the first of this class of drugs to be evaluated, has been found to be active against MRSA $\left(\mathrm{MIC}_{90}\right.$ less than $\left.1.0 \mu \mathrm{g} / \mathrm{mL}\right)$, and also appears to be more potent in vitro than vancomycin and quinupristindalfopristin (100).

The available data for all of these investigational compounds are limited, and many of these drugs are currently undergoing phase II and III studies. Although the preliminary results with these agents are promising, further clinical studies are required in order to determine their comparative efficacy and safety, and to determine their potential role in the management of MRSA infections.

\section{VISA and VRSA strains}

The clinical experience in treating infections caused by VISA and VRSA is limited. However, thus far these strains have generally been susceptible to TMP-SMX, tetracycline and linezolid; one clinical isolate was reported to be resistant to quinupristindalfopristin $(30,31,101)$. Patients have been treated with a variety of antimicrobial agents, often in combination, including vancomycin, aminoglycosides, TMP-SMX, rifampin, doxycycline and linezolid $(30,101)$.

\section{TREATMENT OF MRSA COLONIZATION}

Eradication of MRSA carriage (decolonization), if effective, could be used to prevent the development of subsequent infection in colonized patients or as part of infection control strategies to limit transmission of the organism in health care settings. There are clinical trials of eradication therapy in colonized health care workers (generally healthy adults) (102-104). However, there are fewer data available determining the effectiveness of such therapy in hospitalized patients. An important consideration in evaluating the efficacy of treatment to eradicate MRSA is the extent of colonization. It may be more difficult to eradicate MRSA from individuals with extranasal sites of colonization such as the perineum, wounds or catheter exit sites (105). Other relevant factors include the susceptibility of the MRSA strain to the antimicrobial agent being used for 
TABLE 2

Summary of characteristics and results of clinical trials of antimicrobial agents used for eradication of methicillin-resistant Staphylococcus aureus (MRSA) colonization

\begin{tabular}{|c|c|c|c|c|}
\hline Reference (year) & $\mathbf{n}$ & Interventions & Length of follow-up (days) & Results \\
\hline $53(1990)$ & 21 & $\begin{array}{l}\text { Ciprofloxacin } \\
+ \text { rifampin } \times 14 \text { days } \\
\text { vs TMP-SMX } \\
\text { + rifampin } \times 14 \text { days }\end{array}$ & 180 & $\begin{array}{l}30 \% \text { eradication with } \\
\text { ciprofloxacin vs } \\
40 \% \text { with TMP-SMX } \\
\text { (RR } 0.6 ; 95 \% \mathrm{CI} 0.2 \text { to } 1.9 \text { ) }\end{array}$ \\
\hline $106(1993)$ & 80 & $\begin{array}{l}\text { Novobiocin } \\
+ \text { rifampin } \times 7 \text { days } \\
\text { vs TMP-SMX } \\
+ \text { rifampin } \times 7 \text { days }\end{array}$ & 14 & $\begin{array}{l}67 \% \text { eradication with } \\
\text { novobiocin vs } \\
53 \% \text { with TMP-SMX } \\
\text { (RR } 1.3 ; 95 \% \mathrm{CI} 0.9 \text { to } 1.6 \text { ) }\end{array}$ \\
\hline 107 (1994) & 35 & $\begin{array}{l}\text { Rifampin } \times 5 \text { days vs } \\
\text { minocycline } \times 5 \text { days vs } \\
\text { rifampin }+ \text { minocycline } \times 5 \text { days } \\
\text { vs no treatment }\end{array}$ & 90 & $\begin{array}{l}70 \% \text { eradication with rifampin } \\
\text { vs } 14 \% \text { with no treatment } \\
\text { (RR } 4.9,95 \% \text { Cl } 0.8 \text { to } 31.5 \text { ); } \\
38 \% \text { eradication with minocycline } \\
\text { vs } 14 \% \text { with no treatment } \\
\text { (RR } 2.6 ; 95 \% \text { Cl } 0.35 \text { to } 19.9 \text { ) } \\
50 \% \text { eradication with rifampin + } \\
\text { minocycline vs } 14 \% \text { with no treatment } \\
\text { (RR } 3.5 ; 95 \% \text { Cl } 0.5 \text { to } 23.8 \text { ) }\end{array}$ \\
\hline 108 (1995) & 72 & $\begin{array}{l}\text { Mupirocin ointment } \times 5 \text { days } \\
\text { vs fusidic acid ointment } \\
+ \text { TMP-SMX } \times 5 \text { days }\end{array}$ & 90 & $\begin{array}{l}74 \% \text { eradication with mupirocin } \\
\text { vs } 71 \% \text { fusidic acid + TMP-SMX } \\
\text { (RR } 1.1 ; 95 \% \mathrm{Cl} 0.6 \text { to } 1.9 \text { ) }\end{array}$ \\
\hline 105 (1999) & 102 & $\begin{array}{l}\text { Mupirocin ointment } \\
\text { vs placebo } \times 5 \text { days }\end{array}$ & 26 & $\begin{array}{l}25 \% \text { eradication with mupirocin } \\
\text { vs } 18 \% \text { with placebo } \\
\text { (RR } 1.4 ; 95 \% \mathrm{Cl} 0.6 \text { to } 3.0 \text { ) }\end{array}$ \\
\hline $109(2000)$ & 16 & $\begin{array}{l}\text { Fusidic acid orally } \times 7 \text { days } \\
\text { vs no treatment }\end{array}$ & 14 to 77 & $\begin{array}{l}33 \% \text { eradication with fusidic acid } \\
\text { vs } 50 \% \text { with no treatment } \\
\text { (RR } 0.7 ; 95 \% \text { Cl } 0.2 \text { to } 2.4 \text { ) }\end{array}$ \\
\hline
\end{tabular}

TMP/SMX Trimethoprim-sulphamethoxazole; Vs Versus

decolonization. Moreover, persistence of MRSA colonization may actually be due to the acquisition of a new strain of MRSA rather than failure of eradication therapy. These factors need to be considered when evaluating the efficacy of antimicrobial agents for eradicating MRSA colonization.

Six randomized, controlled trials of topical or systemic agents used for MRSA decolonization in hospitalized or long term care facility patients have been reported (53,105-109) and are summarized in Table 2. A variety of drugs was used, including topical and oral agents. Three of the trials included a placebo or no treatment group. The percentage of patients with nasal MRSA colonization alone was reported in five studies and ranged from $26 \%$ to $100 \%$ (105-109). Percentages of cutaneous site (including ischemic or decubitus ulcers) colonization were reported in four studies and ranged from $7 \%$ to $46 \%(105,106,108,109)$. Eradication of MRSA on day 14 posttreatment was the most frequently reported outcome. Only one study reported the occurrence of MRSA infection (105). Five of the studies were conducted in acute care hospitals $(53,105,106,108,109)$ and one in long term care facilities (107). No statistically significant difference in overall MRSA eradication was identified in any of the studies, although most were small and not adequately powered. The confidence intervals were generally wide and do not exclude clinically important effects. In one study, mupirocin was found to be less effective in eradicating extranasal MRSA than was topical fusidic acid and oral TMP-SMX (108).

Only one study reported data regarding MRSA infection as an outcome: Harbarth et al (105) randomized 102 patients in a Swiss university hospital to five days of treatment with mupirocin ointment or to placebo. Ten MRSA infections occurred (five skin or wound infections, four urinary infections and one osteomyelitis). Three (7\%) infections were in the mupirocin group and seven (14\%) in the placebo group (RR 0.47; 95\% CI 0.13 to 1.70 ).

These clinical trials also examined the emergence of antimicrobial resistance to the agents used. In one study, strains with low level resistance to mupirocin (MIC 8 to $64 \mu \mathrm{g} / \mathrm{mL}$ ) were documented in 23 participants (11 in the mupirocin group and 12 in the placebo group) but no isolates demonstrated higher levels of resistance (110). In the study by Chang et al (109), all pretreatment isolates were susceptible to fusidic acid but, following treatment with this agent, resistance developed in two strains. Similarly, Muder et al (107) found increased rifampin MICs in four patients receiving rifampin, and an increase in minocycline MICs was noted in post-therapy isolates from three patients. Resistance to ciprofloxacin and rifampin developed in MRSA isolates from patients treated with these drugs (53). In contrast, none of the strains from 12 patients treated with either mupirocin or fusidic acid and 
TMP-SMX who had a relapse of MRSA developed resistance in the study by Parras et al (108).

Adverse events were reported in three of the clinical trials $(53,106,108)$. Nasal discomfort was associated with use of topical agents (mupirocin or fusidic acid) (108). Nausea and vomiting due to TMP-SMX, ciprofloxacin or rifampin were reported $(53,108)$. Leukopenia or abnormal liver function tests were also identified in a small number of individuals receiving either rifampin or TMP-SMX $(53,106)$.

In summary, there is insufficient evidence to support use of topical or systemic antimicrobial therapy for eradicating nasal or extranasal colonization with MRSA. There is no demonstrated superiority of either topical or systemic therapy, nor of a combination of these agents. The use of topical or systemic drugs can lead to the development of resistance to the antimicrobial agent used for eradication.

\section{INFECTION CONTROL STRATEGIES FOR THE MANAGEMENT OF MRSA IN HOSPITALS}

A variety of infection control measures has been recommended for the management of hospitalized patients with MRSA infection or colonization in order to prevent transmission of the organism (111-113). Recommendations have included screening or surveillance to identify asymptomatic MRSA carriers, meticulous hand hygiene when providing patient care, implementation of isolation or barrier precautions, cohort nursing, decolonization therapy of colonized patients, and screening and decolonization of health care providers. The effectiveness of handwashing in removing MRSA from the hands of health care providers was demonstrated 20 years ago (11). However, the effectiveness of most other individual control measures has rarely been evaluated because several control measures have generally been implemented concurrently to control an outbreak or to lower endemic MRSA infection rates.

\section{Screening and surveillance}

Studies have demonstrated that isolation of patients identified as having MRSA from clinical specimens only was unsuccessful in controlling MRSA transmission or reducing nosocomial MRSA rates $(11,114)$. In contrast, screening high risk patients for the presence of MRSA followed by implementation of isolation or barrier precautions for those found to be infected or colonized has been shown to be effective in controlling MRSA outbreaks in hospitals and long term care facilities (115-119), and in reducing nosocomial transmission and overall prevalence in facilities where MRSA is endemic (11,110,120-125). Jernigan et al $(118,121)$ reported a 15 -fold decrease in transmission of MRSA in a hospital when colonized patients were recognized by a screening program and then cared for with isolation precautions, compared with when isolation precautions were used only in patients recognized to have MRSA from clinical specimens. Screening patients admitted to a high risk in-patient unit, such as an intensive care unit, was found to be successful in reducing MRSA acquisition rates from $5.8 \%$ to $2.6 \%(\mathrm{P}=0.002)$ and this was associated with a significant decrease in MRSA infection rates (123). Several studies have also documented that screening programs to identify colonized patients with MRSA are cost effective in limiting nosocomial transmission of MRSA $(121,124,126)$.

Although extremely variable, MRSA carriage tends to be prolonged, for months or even years. The half-life of
MRSA colonization in patients previously known to have been MRSA carriers and then subsequently readmitted to hospital has been estimated to be approximately 40 months (127). Therefore, it has been recommended that an 'alert' system be implemented to identify patients previously known to have had MRSA on readmission to hospital so that they can be screened and placed into isolation if appropriate. Outcomes associated with this recommendation have not been evaluated.

\section{Isolation and barrier precautions}

Contamination of the inanimate hospital environment of patients with MRSA occurs frequently. In one study, $69 \%$ to $73 \%$ of the rooms with MRSA patients were contaminated (128). Moreover, the gloved hands of personnel entering the rooms of MRSA patients frequently became contaminated by touching contaminated environmental surfaces even without direct contact with patients (128). Gowns worn by health care providers also often became contaminated. These findings support recommendations for use of a private room, gloves and gowns when caring for patients with MRSA infection or colonization. Jernigan et al (118) reported that contact isolation (private room; use of gloves for manual contact with the patient or potentially contaminated surfaces; gown use for direct patient contact; mask worn when within $1.5 \mathrm{~m}$ of the patient) interrupted nosocomial transmission of MRSA. MRSA transmission was 16 times more frequent from nonisolated patients compared with those in isolation.

Screening high risk patients and subsequent implementation of barrier precautions (such as contact isolation) resulted in reduced MRSA transmission and in a 30\% reduction in MRSA infections in one study (124). Moreover, a cost benefit analysis determined that this strategy would be cost effective even with just a $14 \%$ reduction in MRSA infection rates. At the University Hospitals of Geneva, the implementation of control measures that included high risk patient screening, contact isolation, a computerized 'alert' system and a hand hygiene campaign was followed by a decrease in nosocomial MRSA rates from 0.60 cases per 100 admissions in 1993 to 0.24 cases per 100 admissions in $1997(\mathrm{P}<0.001)(110)$. This was also associated with a decrease in MRSA infection rates and bacteremia rates.

\section{Decolonization of colonized patients or staff}

Decolonization therapy of colonized hospital in-patients has been used to reduce the reservoir of MRSA during outbreaks (129-131). This strategy has been effective when combined with other interventions including MRSA screening and implementation of barrier precautions. Similarly, decolonization therapy of hospital health care providers with nasal MRSA colonization has also been used as part of outbreak management $(129,130,132)$. However, because decolonization therapy has invariably been implemented concurrently with other interventions, it is difficult to determine the attributable effect of this strategy.

\section{RECOMMENDATIONS}

Specific recommendations for the management of patients infected or colonized with MRSA are listed below. The recommendations have been classified into five levels based on the quality of evidence (Table 3) and have been used previously in Position Papers of the Canadian Infectious Disease Society 
(133). Specific infection prevention and control guidelines are not included but interested readers may refer to published guidelines $(12,111,112,134)$.

\section{Treatment of MRSA infection}

Vancomycin is the treatment of choice for serious or invasive MRSA infections (Level II).

Alternative agents that may be considered for the treatment of MRSA infections include clindamycin, TMP-SMX, minocycline, quinupristin-dalfopristin or linezolid, provided the organism is susceptible in vitro to these agents (Level II). Insufficient data are available to make any recommendations regarding the effectiveness of drug combinations for the treatment of MRSA infections.

\section{Eradication of MRSA colonization}

At present, there is insufficient evidence to support the routine use of topical or systemic antimicrobial therapy for eradicating MRSA colonization in patients (Level IV).

\section{REFERENCES}

1. Panlilio AL, Culver DH, Gaynes RP, et al. Methicillin-resistant Staphylococcus aureus in US hospitals, 1975-1991. Infect Control Hosp Epidemiol 1992;13:582-6.

2. Turnridge J, Lawson P, Munro R, Benn R. A national survey of antimicrobial resistance in Staphylococcus aureus in Australian teaching hospitals. Med J Aust 1989;150:65-72.

3. Voss A, Milatovic D, Wallrauch-Schwarz C, Rosdahl VT, Braveny I. Methicillin-resistant Staphylococcus aureus in Europe. Eur J Clin Microbiol Infect Dis 1994;13:50-5.

4. Ayliffe GA. The progressive intercontinental spread of methicillinresistant Staphylococcus aureus. Clin Infect Dis 1997;24(Suppl 1):S74-9.

5. Low DE, Garcia M, Callery S, et al. Methicillin-resistant Staphylococcus aureus - Ontario. Can Dis Weekly Report 1981;7:249-50.

6. Simor AE, Ofner-Agostini M, Bryce E, et al. The evolution of methicillin-resistant Staphylococcus aureus in Canadian hospitals: 5 years of national surveillance. Can Med Assoc J 2001;165:21-6.

7. Simor AE, Ofner-Agostini M, Mulvey M, et al. Methicillin-resistant Staphylococcus aureus (MRSA) surveillance in Canada, 1995-2001. 10th International Symposium on Staphylococci and Staphylococcal Infection, Tsukuba, Japan, October 16-19, 2002. (Abst)

8. McGeer A, Fleming CA, Green KA, Willey BM, Low DE. Antimicrobial resistance in Ontario hospitals: Transmission control programs begin to pay off. Laboratory Proficiency Test Program Newslett 2002;32:1-4

9. Embil J, Ramotar K, Romance L, et al. Methicillin-resistant Staphylococcus aureus in tertiary care institutions on the Canadian prairies, 1990-1992. Infect Control Hosp Epidemiol 1994;15:646-51.

10. Kurbis CA, Wylie JL. Community-based cluster of methicillin-resistant Staphylococcus aureus in Manitoba. Can J Infect Dis 2001;12:149-52.

11. Thompson RL, Cabezudo I, Wenzel RP. Epidemiology of nosocomial infections caused by methicillin-resistant Staphylococcus aureus. Ann Intern Med 1982;97:309-17.

12. Boyce JM, Jackson MM, Pugliese G, et al. Methicillin-resistant Staphylococcus aureus (MRSA): A briefing for acute care hospitals and nursing facilities. Infect Control Hosp Epidemiol 1994;15:105-15.

13. Layton MC, Hierholzer WJ Jr, Patterson JE. The evolving epidemiology of methicillin-resistant Staphylococcus aureus at a university hospital. Infect Control Hosp Epidemiol 1995;16:12-7.

14. Monnet DL. Methicillin-resistant Staphylococcus aureus and its relationship to antimicrobial use: Possible implications for control. Infect Control Hosp Epidemiol 1998;19:552-9.

15. Warshawsky B, Hussain Z, Gregson DB, et al. Hospital- and community-based surveillance of methicillin-resistant Staphylococcus aureus: Previous hospitalization is the major risk factor. Infect Control Hosp Epidemiol 2000;21:724-7.

16. Pujol M, Peña C, Pallares R, et al. Nosocomial Staphylococcus aureus bacteremia among nasal carriers of methicillin-resistant and methicillin-susceptible strains. Am J Med 1996;100:509-16.
Table 3

Classification of level of evidence for recommendations*

\begin{tabular}{ll}
\hline Level of evidence & Definition \\
\hline Level I & Based on randomized, controlled trials (or meta-analysis
\end{tabular}

$\begin{array}{ll}\text { Level I } & \text { Based on randomized, controlled trials (or meta-analysis } \\ \text { of such trials) of adequate size to ensure a low risk of }\end{array}$

incorporating false-positive or false-negative results

Level II

Based on randomized, controlled trials that are too small to provide Level I evidence. These may show either positive trends that are not statistically significant or no trends, and are associated with a high risk of false-negative results

Level III Based on nonrandomized, controlled or cohort studies, case series, case controlled studies or cross-sectional studies

Level IV Based on the opinion of respected authorities or that of expert committees as indicated in published consensus conferences or guidelines

*This classification scheme has been previously used in Canadian Infectious Disease Society Position Papers (133)

17. Law MR, Gill ON. Hospital-acquired infection with methicillinresistant and methicillin-sensitive staphylococci. Epidemiol Infect 1988;101:623-9.

18. Stamm AM, Long MN, Belcher B. Higher overall nosocomial infection rate because of increased attack rate of methicillin-resistant Staphylococcus aureus. Am J Infect Control 1993;21:70-4.

19. Wakefield DS, Helms CM, Massanari RM, Mori M, Pfaller M. Cost of nosocomial infection: Relative contributions of laboratory, antibiotic, and per diem costs in serious Staphylococcus aureus infections. Am J Infect Control 1988;16:185-92.

20. Ibelings MMS, Bruining HA. Methicillin-resistant Staphylococcus aureus: Acquisition and risk of death in patients in the intensive care unit. Eur J Surg 1998;164:411-8.

21. Romero-Vivas J, Rubio M, Fernandez C, Picazo JJ. Mortality associated with nosocomial bacteremia due to methicillin-resistant Staphylococcus aureus. Clin Infect Dis 1995;21:1417-23.

22. Conterno LO, Wey SB, Castelo A. Risk factors for mortality in Staphylococcus aureus bacteremia. Infect Control Hosp Epidemiol 1998;19:32-7.

23. Whitby M, McLaws H-L, Berry G. Risk of death from methicillinresistant bacteraemia: A meta-analysis. Med J Aust 2001;175:264-7.

24. Rubin RJ, Harrington CA, Poon A, Dietrich K, Greene JA, Moiduddin A. The economic impact of Staphylococcus aureus infection in New York City hospitals. Emerg Infect Dis 1999;5:9-17.

25. Kim T, Oh PI, Simor AE. The economic impact of methicillinresistant Staphylococcus aureus in Canadian hospitals. Infect Control Hosp Epidemiol 2001;22:99-104.

26. Hiramatsu K. Reduced susceptibility of Staphylococcus aureus to vancomycin - Japan 1996. MMWR 1997;46:624-6.

27. Hiramatsu K, Hanaki H, Ino T, Yabuta K, Oguri T, Tenover FC. Methicillin-resistant Staphylococcus aureus clinical strain with reduced vancomycin susceptibility. J Antimicrob Chemother 1997;40:135-6.

28. Ploy MC, Grélaud C, Martin C, de Lumley L, Denis F. First clinical isolate of vancomycin-intermediate Staphylococcus aureus in a French hospital. Lancet 1998;351:1212.

29. Smith TL, Pearson ML, Wilcox KR, et al. Emergence of vancomycin resistance in Staphylococcus aureus. N Engl J Med 1999;340:493-501.

30. Tenover FC, Biddle JW, Lancaster MV. Increasing resistance to vancomycin and other glycopeptides in Staphylococcus aureus. Emerg Infect Dis 2001;7:327-32.

31. Sievert DM, Boulton ML, Stoltman G, et al. Staphylococcus aureus resistant to vancomycin - United States, 2002. MMWR 2002;51:565-7.

32. Miller D, Urdaneta V, Weltman A. Vancomycin-resistant Staphylococcus aureus - Pennsylvania, 2002. MMWR 2002;51:902.

33. Chambers HF. Methicillin-resistant staphylococci. Clin Microbiol Rev 1988;1:173-86.

34. Mulligan ME, Murray-Leisure KA, Ribner BS, et al. Methicillinresistant Staphylococcus aureus : A consensus review of the microbiology, pathogenesis, and epidemiology with implications for prevention and management. Am J Med 1993;94:313-28. 
35. Michel M, Gutmann L. Methicillin-resistant Staphylococcus aureus and vancomycin-resistant enterococci: Therapeutic realities and possibilities. Lancet 1997;349:1901-6.

36. Rahman M. Alternatives to vancomycin in treating methicillinresistant Staphylococcus aureus infections. J Antimicrob Chemother 1998;41:325-8.

37. Karchmer AW. Staphylococcus aureus and vancomycin: The sequel. Ann Intern Med 1991;115:739-41.

38. Levine DP, Fromm S, Reddy BR. Slow response to vancomycin or vancomycin plus rifampin in methicillin-resistant Staphylococcus aureus endocarditis. Ann Intern Med 1991;115:674-80.

39. Gentry CA, Rodvold KA, Novak RM, Hershow RC, Naderer OJ. Retrospective evaluation of therapies for Staphylococcus aureus endocarditis. Pharmacotherapy 1997;17:990-7.

40. Ackerman H, Vannier AM, Eudy EB. Analysis of vancomycin time-kill studies with Staphylococcus aureus species by using a curve stripping program to describe the relationship between concentration and pharmacodynamic response. Antimicrob Agents Chemother 1992;36:1766-9.

41. Van Laethem V, Hermans P, De Wit S, Goosens, H, Clumeck N. Teicoplanin compared with vancomycin in methicillin-resistant Staphylococcus aureus infections: Preliminary results. J Antimicrob Chemother 1988;21(Suppl A):81-7.

42. Wood MJ. The comparative efficacy and safety of teicoplanin and vancomycin. J Antimicrob Chemother 1996;37:209-22.

43. Smith SM, Mangia A, Eng RH, et al. Clindamycin for colonization and infection with MRSA. Infection 1988;16:95-7.

44. Maple PA, Hamilton-Miller J, Brumfitt W. World-wide antibiotic resistance in methicillin-resistant Staphylococcus aureus . Lancet 1989;1:537-40.

45. Reeves DS, Holt HA, Phillips I, et al. Activity of clindamycin against Staphylococcus aureus and Staphylococcus epidermidis from four UK centres. J Antimicrob Chemother 1991;27:469-74.

46. Nicola FG, McDougal LK, Biddle JW, Tenover FC. Characterization of erythromycin-resistant isolates of Staphylococcus aureus recovered in the United States from 1958 through 1969. Antimicrob Agents Chemother 1998;42:3024-7.

47. Trzcinski K, Cooper BS, Hryniewicz W, Dowson CG. Expression of resistance to tetracyclines in strains of methicillin-resistant Staphylococcus aureus . J Antimicrob Chemother 2000;45:763-70.

48. Kuwabara K, Shigeoka H, Otonari T, Kodoma T, Takii M. Successful treatment with minocycline of two cases of endocarditis caused by Staphylococcus. Chemotherapy 1985;33:904.

49. Lawlor MT, Sullivan MC, Levitz RE, Quintiliani R, Nightingale C. Treatment of prosthetic valve endocarditis due to methicillinresistant Staphylococcus aureus with minocycline. J Infect Dis 1990;161:812-4.

50. Tamer MA, Bray JD. Trimethoprim-sulfamethoxazole treatment of multiantibiotic-resistant staphylococcal endocarditis and meningitis. Clin Pediatr 1986;17:75-82.

51. Markowitz N, Quinn EL, Saravolatz LD. Trimethoprimsulfamethoxazole compared with vancomycin for the treatment of Staphylococcus aureus infection. Ann Intern Med 1992;117:390-8.

52. Neu HC. Quinolones: A new class of antimicrobial agents with wide potential uses. Med Clin North Am 1988;72:623-36.

53. Peterson LR, Quick JN, Jensen B, et al. Emergence of ciprofloxacin resistance in nosocomial methicillin-resistant Staphylococcus aureus isolates. Resistance during ciprofloxacin plus rifampin therapy for methicillin-resistant $S$ aureus colonization. Arch Intern Med 1990;150:2151-5.

54. Blumerg HM, Rimland D, Carroll DJ, Terry P, Wachsmuth IK. Rapid development of ciprofloxacin resistance in methicillinsusceptible and -resistant Staphylococcus aureus . J Infect Dis 1991;163:1279-85.

55. Piddock LJV. New quinolones and gram-positive bacteria. Antimicrob Agents Chemother 1994;38:163-9.

56. Fass RJ. In vitro activity of Bay y 3118, a new quinolone. Antimicrob Agents Chemother 1993;37:2348-57.

57. Blondeau JM. A review of the comparative in-vitro activities of 12 antimicrobial agents, with a focus on five new 'respiratory quinolones'. J Antimicrob Chemother 1999;43(Suppl B):1-11.

58. Lowe MN, Lamb HM. Gemifloxacin. Drugs 2000;59:1137-47.

59. Tuazon CU, Lin MYC, Sheagren JN. In vitro activity of rifampin alone and in combination with nafcillin and vancomycin against pathogenic strains of Staphylococcus aureus . Antimicrob Agents Chemother 1978;13:759-61.
60. Sande MA, Mandell GL. Effect of rifampin on carriage of nasal Staphylococcus aureus . Antimicrob Agents Chemother 1975;7:294-7.

61. Hackbarth CJ, Chambers HF, Sande MA. Serum bactericidal activity of rifampin in combination with other antimicrobial agents against Staphylococcus aureus. Antimicrob Agents Chemother 1986;29:611-3.

62. Simon UC, Simon M. Antibacterial activity of teicoplanin and vancomycin in combination with rifampicin, fusidic acid, or fosfomycin against staphylococci on vein catheters. Scand J Infect Dis 1990;72(Suppl):14-9.

63. Faville RJ, Zaske DE, Kaplan EL, Croslley K, Sabath LD, Quie PG. Staphylococcus aureus endocarditis: Combined therapy with vancomycin and rifampin. JAMA 1984;240:1963-5.

64. Watanakunakorn C, Guerriero JC. Interaction between vancomycin and rifampin against Staphylococcus aureus . Antimicrob Agents Chemother 1981;19:1089-91.

65. Verbist L. The antimicrobial activity of fusidic acid. J Antimicrob Chemother 1990;25(Suppl B):1-5.

66. Shanson DC. Clinical relevance of resistance to fusidic acid in Staphylococcus aureus . J Antimicrob Chemother 1990;25(Suppl B):15-21.

67. Fantin B, Leclercq R, Duval J, Carbon C. Fusidic acid alone or in combination with vancomycin for therapy of experimental endocarditis due to methicillin-resistant Staphylococcus aureus . Antimicrob Agents Chemother 1993;37:2466-9.

68. Portier H. A multicentre, open, clinical trial of a new intravenous formulation of fusidic acid in severe staphylococcal infection. J Antimicrob Chemother 1990;25(Suppl B):39-44.

69. Besnier JM, Kanoun F, Martin C, Cotty P, Fenneteau A, Choutet P. Failure of a combination of vancomycin and fusidic acid in a patient with staphylococcal infection. J Antimicrob Chemother 1991;27:560-2.

70. Lamb HM, Figgitt DP, Faulds D. Quinupristin/dalfopristin. A review of its use in the management of serious gram-positive infections. Drugs 1999;58:1061-97.

71. Leclercq R, Nantas L, Soussy CJ, Duval J. Activity of RP59500, a new parenteral semisynthetic streptogramin against staphylococci with various mechanisms of resistance to macrolide lincosamide streptogramin antibiotics. J Antimicrob Chemother 1992;30(Suppl A):67-75.

72. Anwer S, Keefer MC, Evans TG. Quinupristin/dalfopristin for treatment of MRSA endocarditis refractory to conventional therapy. Infect Dis Clin Pract 1998;7:414-6.

73. Nichols RL, Graham DR, Barriere SL, et al. Treatment of hospitalized patients with complicated Gram-positive skin and skin structure infections: Two randomized, multicentre studies of quinupristin/dalfopristin versus cefazolin, oxacillin or vancomycin. J Antimicrob Chemother 1999;44:263-73.

74. Scotton PG, Rigoli R, Vagila A. Combination of quinupristin/ dalfopristin and glycopeptide in severe methicillin-resistant staphylococcal infections failing previous glycopeptide regimens. Infection 2002;30:161-3.

75. Drew RH, Perfect JR, Srinath L, Kurkimilis E, Dowzicky M, Talbot GH. Treatment of methicillin-resistant Staphylococcus aureus infections with quinupristin-dalfopristin in patients intolerant of or failing prior therapy. J Antimicrob Chemother 2000;46:775-84.

76. Fagon J-Y, Patrick H, Haas DW, et al. Treatment of gram-positive nosocomial pneumonia. Prospective randomized comparison of quinupristin/dalfopristin versus vancomycin. Nosocomial Pneumonia Group. Am J Respir Crit Care Med 2000;161:753-62.

77. Dowzicky M, Talbot GH, Feger C, Prokocimer P, Etienne J, Leclercq R. Characterization of isolates associated with emerging resistance to quinupristin/dalfopristin (Synercid®) during a worldwide clinical program. Diagn Microbiol Infect Dis 2000;37:57-62.

78. Werner G, Cuny C, Schmitz F-J, Witte W. Methicillin-resistant, quinupristin-dalfopristin-resistant Staphylococcus aureus with reduced susceptibility to glycopeptides. J Clin Microbiol 2001;39:3586-90.

79. Johnson AP, Warner M, Livermore DM. Activity of linezolid against multi-resistant Gram-positive bacteria from diverse hospitals in the United Kingdom. J Antimicrob Chemother 2000;45:225-30.

80. Mulazimoglu L, Drenning SD, Yu VL. In vitro activities of two novel oxazolidinones (U100592 and U100766), a new fluoroquinolone (trovafloxacin), and dalfopristin-quinupristin 
against Staphylococcus aureus and Staphylococcus epidermidis. Antimicrob Agents Chemother 1996;40:2428-230.

81. Gerson SL, Kaplan SL, Bruss JB, et al. Hematologic effects of linezolid: Summary of clinical experience. Antimicrob Agents Chemother 2002;46:2723-6.

82. Chien JW, Kucia ML, Salata RA. Use of linezolid, an oxazolidinone, in the treatment of multidrug-resistant gram-positive bacterial infections. Clin Infect Dis 2000;30:146-51.

83. Ruiz ME, Guerrero IC, Tuazon CU. Endocarditis caused by methicillin-resistant Staphylococcus aureus : Treatment failure with linezolid. Clin Infect Dis 2002;35:1018-20.

84. Tsiodras S, Gold HS, Sakoulas G, et al. Linezolid resistance in a clinical isolate of Staphylococcus aureus. Lancet 2001;358:207-8.

85. Stevens DL, Herr D, Lampiris H, Hunt JL, Batts DH, Hafkin B. Linezolid versus vancomycin for the treatment of methicillinresistant Staphylococcus aureus infections. Clin Infect Dis 2002;34:1481-90.

86. Rubinstein E, Cammarata S, Oliphant T, Wunderink R, Linezolid Pneumonia Study Group. Linezolid (PNU-100766) versus vancomycin in the treatment of hospitalized patients with nosocomial pneumonia: A randomized, double-blind, multicentre study. Clin Infect Dis 2001;32:402-12.

87. Rittenhouse BE, Li Z, Willke RJ, Hafkin B. Hospital length of stay reduction in dischargeable patients: Evidence from a randomized clinical trial of methicillin-resistant staphylococci infections: Linezolid vs. vancomycin. 41st Annual Interscience Conference on Antimicrobial Agents and Chemotherapy, Chicago, Illinois, USA, 2001. (Abst O-398)

88. Swenson JM, Tenover FC. In vitro activity of a new cephalosporin, RWJ-54428, against streptococci, enterococci and staphylococci, including glycopeptide-intermediate Staphylococcus aureus . J Antimicrob Chemother 2002;49:845-50.

89. Chambers HF. In vitro and in vivo antistaphylococcal activities of L-695,256, a carbapenem with high affinity for the penicillinbinding protein PBP 2a. Antimicrob Agents Chemother 1995;39:462-6.

90. Sumita Y, Nouda H, Kamazawa K, Fukasawa M. Antimicrobial activities of SM-17466, a novel carbapenem antibiotic with potent activity against methicillin-resistant Staphylococcus aureus . Antimicrob Agents Chemother 1995;39:910-6.

91. Mercier RC, Houlihan HH, Ryback MJ. Pharmacodynamic evaluation of a new glycopeptide, LY333328, and in-vitro activity against Staphylococcus aureus and Enterococcus faecium. Antimicrob Agents Chemother 1997;41:1307-12.

92. Okamoto R, Sato Y, Hosaka Y, Nakano R, Kaieda S, Inoue M. In vitro activity of AZD2563, the new oxazolidinone, against clinical isolates of gram-positive cocci, including multi-resistant strains. 41st Annual Interscience Conference on Antimicrobial Agents and Chemotherapy, Chicago, Illinois, USA, 2001. (Abst F-1028)

93. Weiss WJ, Jacobus NV, Petersen PJ, Testa RT. Susceptibility of enterococci, methicillin-resistant Staphylococcus aureus and Streptococcus pneumoniae to the glycylcyclines. J Antimicrob Chemother 1995;36:225-30.

94. Gordon KA, Pfaller MA, Jones RN, SENTRY Participants Group. BMS 284756 (formerly T-3811, a des-fluoroquinolone) potency and spectrum tested against over 10,000 bacterial bloodstream infection isolates from the SENTRY antimicrobial surveillance programme (2000). J Antimicrob Chemother 2002;49:851-5.

95. Shetty N, Wilson AP. Sitafloxacin in the treatment of patients with infections caused by vancomycin-resistant enterococci and methicillin-resistant Staphylococcus aureus . J Antimicrob Chemother 2000;46:633-8.

96. Hackbarth CJ, Chambers HF. Methicillin-resistant staphylococci: Detection methods and treatment of infections. Antimicrob Agents Chemother 1989;33:995-9.

97. Rybak MJ, Hersherger E, Moldovan T, Grace RG. In vitro activities of daptomycin, vancomycin, linezolid, and quinupristin-dalfopristin against staphylococci and enterococci, including vancomycinintermediate and -resistant strains. Antimicrob Agents Chemother 2000;44:1062-6

98. Kephart PA, Esposito AL. Comparison of the investigational drug LY146032, and vancomycin in experimental pneumonia due to methicillin-resistant Staphylococcus aureus . J Antimicrob Chemother 1988;21:33-9.

99. Thorne GM, Alder J. Daptomycin: A novel lipopeptide antibiotic. Clin Microbiol Newslttr 2002;24:33-40.
100. Jones RN, Hare RS, Sabatelli FJ, Ziracin Susceptibility Testing Group. In vitro Gram-positive antimicrobial activity of evernimicin (SCH-27899), a novel oligosaccharide, compared with other antimicrobials: A multicentre international study. J Antimicrob Chemother 2001;47:15-25.

101. Srinivasan A, Dick JD, Perl TM. Vancomycin resistance in staphylococci. Clin Microbiol Rev 2002;15:430-8.

102. Casewell MW, Hill RL. Elimination of nasal carriage of Staphylococcus aureus with mupirocin ('pseudomonic acid') a controlled trial. J Antimicrob Chemother 1986;17:365-72.

103. Scully BE, Brianes F, Gu JW, Neu HC. Mupirocin treatment of nasal staphylococcal colonization. Arch Intern Med 1992;152:352-6.

104. Fernandez C, Gaspar C, Torrellas A, et al. A double-blind, randomized, placebo-controlled trial to evaluate the safety and efficacy of mupirocin calcium ointment for eliminating nasal carriage of Staphylococcus aureus among hospital personnel. J Antimicrob Chemother 1995;35:339-408.

105. Harbarth S, Dharan S, Liassine N, Herrault P, Auckenthaler R, Pittet D. Randomized, placebo-controlled trial of mupirocin for eradicating carriage of methicillin-resistant Staphylococcus aureus . Antimicrob Agents Chemother 1999;43:1412-6.

106. Walsh TJ, Standiford HC, Reboli AC, et al. Randomized doubleblinded trial of rifampin with either novobiocin or trimethoprimsulfamethoxazole against methicillin-resistant Staphylococcus aureus colonization: Prevention of antimicrobial resistance and effect of host factors on outcome. Antimicrob Agents Chemother 1993;37:1334-42.

107. Muder RR, Boldin M, Brennen C, Hsieh M, Vickers RM, Yee YC. A controlled trial of rifampicin, minocycline, and rifampicin plus minocycline for eradication of methicillin-resistant Staphylococcus aureus in long-term care patients. J Antimicrob Chemother 1994;34:188-90.

108. Parras F, Guerrero MC, Bouza E, et al. Comparative study of mupirocin and oral co-trimoxazole plus topical fusidic acid in eradication of nasal carriage of methicillin-resistant Staphylococcus aureus . Antimicrob Agents Chemother 1995;39:175-9.

109. Chang SC, Hsieh SM, Chen ML, Sheng WH, Chen YC. Oral fusidic acid fails to eradicate methicillin-resistant Staphylococcus aureus colonization and results in emergence of fusidic acid resistant strains. Diagn Microbiol Infect Dis 2000;36:131-6.

110. Harbarth S, Martin Y, Rohner P, Henry N, Auckenthaler R, Pittet D. Effect of delayed infection control measures on a hospital outbreak of methicillin-resistant Staphylococcus aureus. J Hosp Infect 2000;46:43-9.

111. Arnold MS, Dempsey JM, Fishman M, McAuley PJ, Tibert C, Vallande NC. The best hospital practices for controlling methicillin-resistant Staphylococcus aureus : On the cutting edge. Infect Control Hosp Epidemiol 2002;23:69-76.

112. Ayliffe GAJ, Buckles A, Casewell MW, et al. Revised guidelines for the control of methicillin-resistant Staphylococcus aureus infection in hospitals. J Hosp Infect 1998;39:253-90.

113. Rubinovitch B, Pittet D. Screening for methicillin-resistant Staphylococcus aureus in the endemic hospital: What have we learned? J Hosp Infect 2001;47:9-18.

114. Murray-Leisure KA, Geib S, Gracely D, et al. Control of epidemic methicillin-resistant Staphylococcus aureus . Infect Control Hosp Epidemiol 1990;11:343-50.

115. Bartzokas CA, Paton JH, Gibson MF, Graham R, McLoughlin GA, Croton RS. Control and eradication of methicillin-resistant Staphylococcus aureus on a surgical unit. N Engl J Med 1984;311:1422-5.

116. Dacre J, Emmerson AM, Jenner EA. Gentamicin-methicillinresistant Staphylococcus aureus : Epidemiology and containment of an outbreak. J Hosp Infect 1986;7:130-6.

117. Walsh TJ, Vlahov D, Hansen SL, et al. Prospective microbiologic surveillance in control of nosocomial methicillin-resistant Staphylococcus aureus. Infect Control 1987;8:7-14.

118. Jernigan JA, Titus MG, Gröschel DHM, Getchell-White SI, Farr BM. Effectiveness of contact isolation during a hospital outbreak of methicillin-resistant Staphylococcus aureus. Am J Epidemiol 1996;143:496-504.

119. Kotilainen P, Routamaa M, Peltonen R, et al. Eradication of methicillin-resistant Staphylococcus aureus from a health center 
ward and associated nursing home. Arch Intern Med 2001;161:859-63.

120. Pearman JW, Christiansen KJ, Annear DI, et al. Control of methicillin-resistant Staphylococcus aureus (MRSA) in an Australian metropolitan teaching hospital complex. Med J Aust 1985;142:103-8.

121. Jernigan JA, Clemence MA, Stott GA, et al. Control of methicillinresistant Staphylococcus aureus at a university hospital: One decade later. Infect Control Hosp Epidemiol 1995;16:686-96.

122. Cox RA, Conquest C, Mallaghan C, Marples RR. A major outbreak of methicillin-resistant Staphylococcus aureus caused by a new phage type (EMRSA-16). J Hosp Infect 1995;29:87-106.

123. Girou E, Pujade G, Legrand P, Cizeau F, Brun-Buisson C. Selective screening of carriers for control of methicillin-resistant Staphylococcus aureus (MRSA) in high-risk hospital areas with a high level of endemic MRSA. Clin Infect Dis 1998;27:543-50.

124. Chaix C, Durand-Zaleski I, Alberti C, Brun-Buisson C. Control of endemic methicillin-resistant Staphylococcus aureus . A cost-benefit analysis in an intensive care unit. JAMA 1999;282:1745-51.

125. Mishal J, Sherer Y, Levin Y, Katz D, Embon E. Two-stage evaluation and intervention program for control of methicillin-resistant Staphylococcus aureus in the hospital setting. Scand J Infect Dis 2001;33:498-501.

126. Papia G, Louie M, Tralla A, Johnson C, Collins V, Simor AE. Screening high-risk patients for methicillin-resistant Staphylococcus aureus on admission to the hospital: Is it cost-effective? Infect Control Hosp Epidemiol 1999;20:473-7.

127. Sanford MD, Widmer AF, Bale MJ, Jones RN, Wenzel RP. Efficient detection and long-term persistence of the carriage of methicillin- resistant Staphylococcus aureus . Clin Infect Dis 1994;19:1123-8.

128. Boyce JM, Potter-Bynoe G, Chenevert C, King T. Environmental contamination due to methicillin-resistant Staphylococcus aureus : Possible infection control implications. Infect Control Hosp Epidemiol 1997;18:622-7.

129. Hill RLR, Duckworth GJ, Casewell MW. Elimination of nasal carriage of methicillin-resistant Staphylococcus aureus with mupirocin during a hospital outbreak. J Antimicrob Chemother 1988;22:377-84.

130. Darouiche R, Wright C, Hamill R, Koza M, Lewis D, Markowski J. Eradication of colonization by methicillin-resistant Staphylococcus aureus by using oral minocycline-rifampin and topical mupirocin. Antimicrob Agents Chemother 1991;35:1612-5.

131. Bertino JS Jr . Intranasal mupirocin for outbreaks of methicillinresistant Staphylococcus aureus. Am J Health-Syst Pharm 1997;54:2185-91.

132. Bacon AE, Jorgensen KA, Wilson KH, Kauffman CA. Emergence of nosocomial methicillin-resistant Staphylococcus aureus and therapy of colonized personnel during a hospital-wide outbreak. Infect Control 1987;8:145-50.

133. McKenna S, Evans GA, Canadian Infectious Disease Society Antimicrobial Agents Committee. Macrolides: A Canadian Infectious Disease Society position paper. Can J Infect Dis 2001;12:218-31.

134. Muto CA, Jernigan JA, Ostrowsky BE, et al. SHEA guideline for preventing nosocomial transmission of multidrug-resistant strains of Staphylococcus aureus and Enterococcus. Infect Control Hosp Epidemiol 2003;24:362-86. 


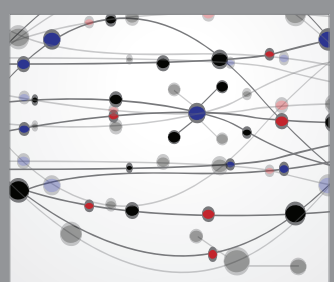

The Scientific World Journal
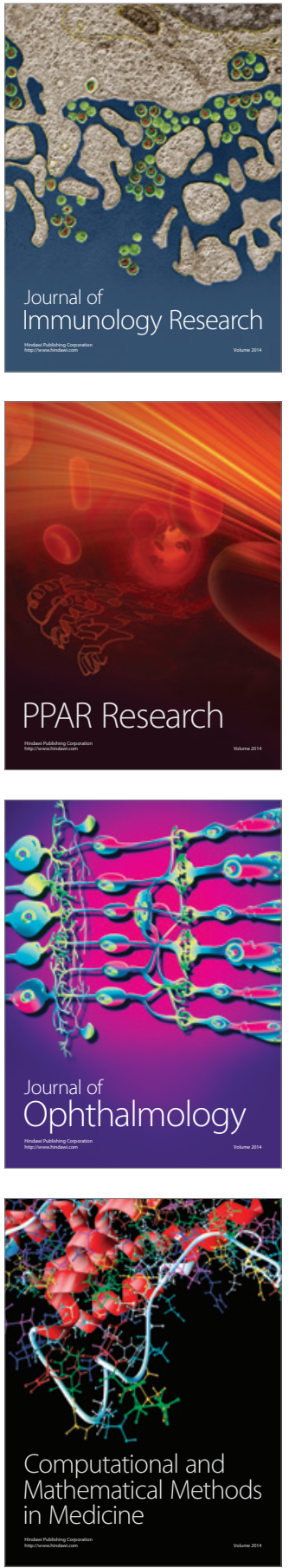

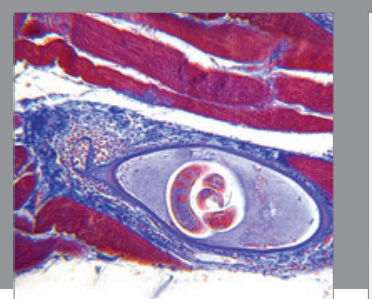

Gastroenterology Research and Practice

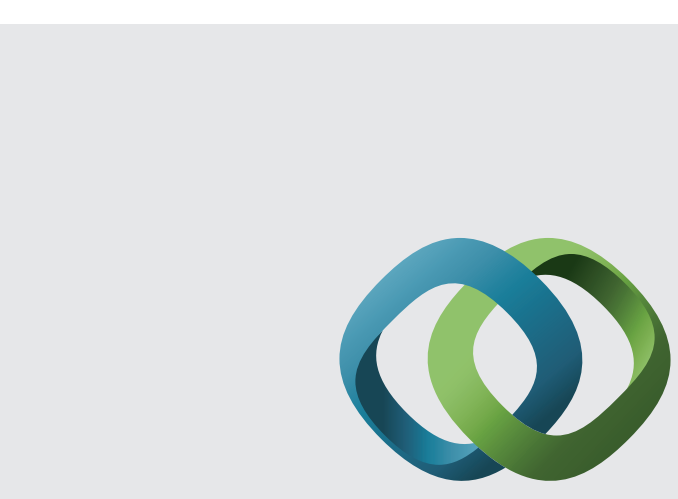

\section{Hindawi}

Submit your manuscripts at

http://www.hindawi.com
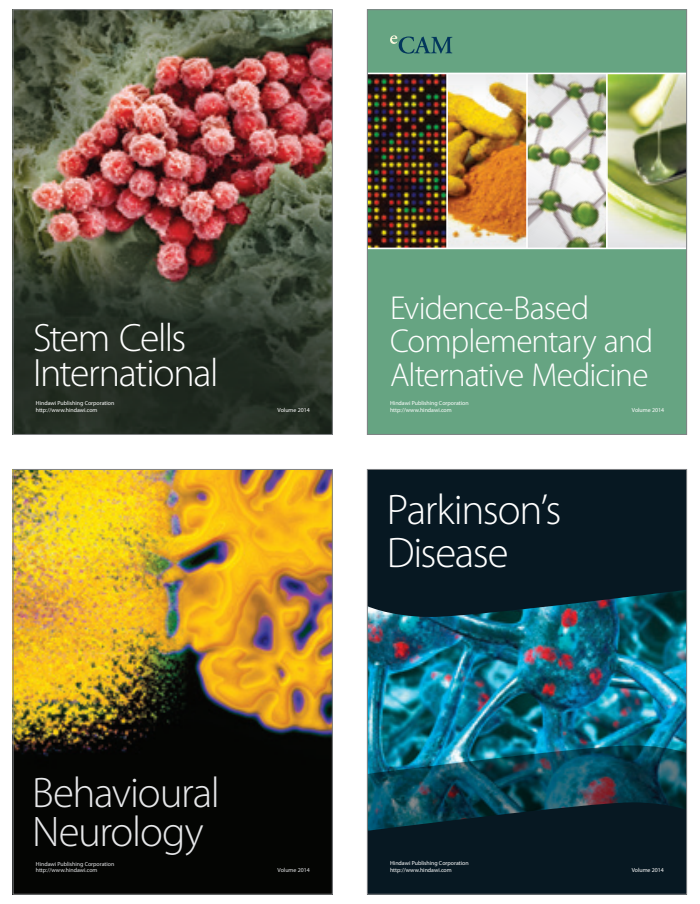
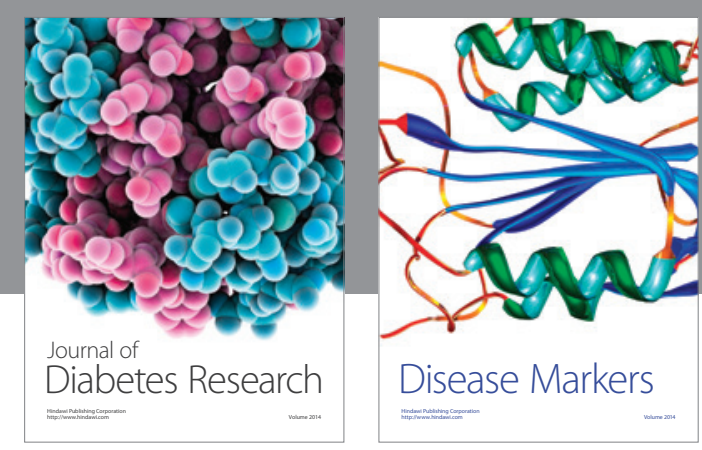

Disease Markers
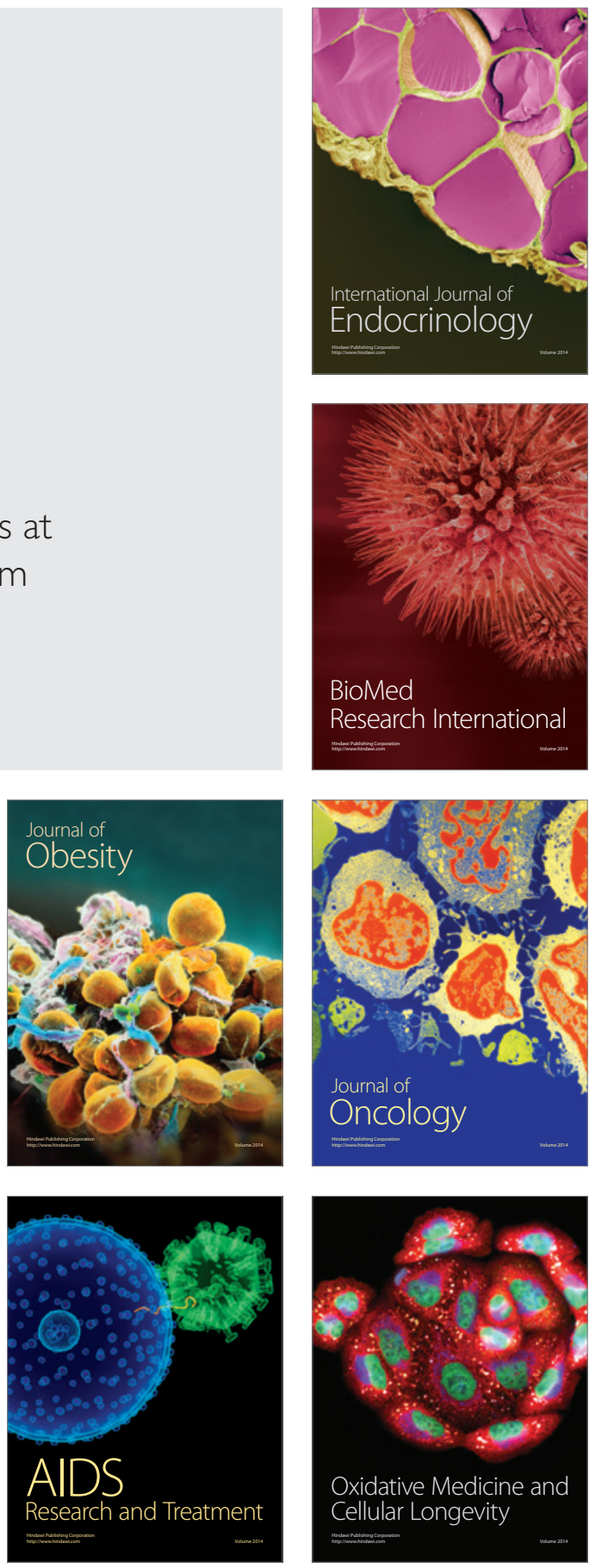